\title{
On the functional overlap between two Drosophila POU homeo domain genes and the cell fate specification of a CNS neural precursor
}

\author{
Su Ling Yeo, Alan Lloyd, ${ }^{1}$ Kevin Kozak, ${ }^{1}$ Ai Dinh,, ${ }^{1}$ Thomas Dick, Xiaohang Yang, \\ Shigeru Sakonju, ${ }^{1}$ and William $\mathrm{Chia}^{2}$ \\ Institute of Molecular and Cell Biology, National University of Singapore, Singapore 0511, Republic of Singapore; ${ }^{1}$ Howard \\ Hughes Medical Institute, Department of Human Genetics, University of Utah School of Medicine, Salt Lake City, Utah \\ 84112 USA
}

\begin{abstract}
The $\sim 200$ distinct neurons comprising each hemisegment of the Drosophila embryonic CNS are derived from a stereotypic array of $\sim 30$ progenitor stem cells, called neuroblasts (NBs). Each NB undergoes repeated asymmetric divisions to produce several smaller ganglion mother cells (GMCs), each of which, in turn, divides to produce two neurons and/or glia cells. To understand the process by which cell type diversity is generated in the CNS, we are focusing on identifying genes that affect cell identity in the NB4-2 lineage from which the RP2 motoneuron is derived. We show here that within the early part of the NB4-2 lineage, two closely linked and structurally related POU homeo domain genes, pdm-2 (dPOU28) and pdm-1 (dPOU19), both encode proteins that accumulate to high levels only in the first GMC (GMC4-2a) and not in its progeny, the RP2 motoneuron. Our results from the genetic and developmental analysis of $p d m-1$ and pdm-2 demonstrate that these genes are not required for the birth of GMC4-2a; however, they are both involved in specifying the identity of GMC4-2a and, ultimately, in the genesis of RP2 neurons, with pdm-2 being the more dominant player in this process. In mutant animals where both $p d m-1$ and $p d m-2$ functions are removed, GMC4-2a fails to express markers consistent with a GMC4-2a identity and no mature (Eve protein expressing) RP2 neurons are produced. We demonstrate that in some mutant combinations in which no mature RP2 neurons are produced, some GMC4-2a cells can nevertheless divide. Hence, the failure of the POU mutants to produce mature RP2 neurons is not attributable to a block in GMC4-2a cell division per se but, rather, because the GMC4-2a cells fail to acquire their correct cellular identity.
\end{abstract}

[Key Words: Drosophila; POU homeo domain; CNS cell fate; redundancy]

Received January 27, 1995; revised version accepted March 29, 1995.

The Drosophila CNS is generated from a stereospecific set of stem cells, neuroblasts (NBs), which are formed by delamination of $\sim 20 \%$ of the cells from the neuroectodermal region (for review, see Artavanis-Tsakonas and Simpson 1991; Campos-Ortega 1993; Jimenez and Modolell 1993|. Most of the genetic elements regulating the formation of $\sim 30 \mathrm{NBs} /$ hemisegment have been identified and analyzed extensively; they are comprised of proneural genes, which impart the potential for neurectodermal cells to adopt the neural path, and the neurogenic genes, which act via a process called lateral inhibition to ensure that the correct number of neuroblasts are formed. Each NB divides assymetrically and repeatedly to give rise to a set of ganglion mother cells (GMCs), and these each divide once to produce neuronal and glia prog-

${ }^{2}$ Corresponding author. eny. In this way, each neuroblast that occupies a unique position within a hemisegment possesses a unique identity and will produce a characteristic family of neurons and glia cells (for review, see Doe 1992a; Goodman and Doe 1993).

To understand how the diversity of neuronal and glia cell types is generated, we need to delineate neuronal cell lineages and also identify the genes involved in the specification of neural cell fate. Two recent developments should greatly facilitate our efforts to define cell lineages (for review, see Doe and Technau 1993). Through the use of molecular markers, it has recently become possible to demonstrate that each Drosophila NB forms at a stereotypic time and position (Doe 1992b), improving the resolution of previously constructed NB maps (Hartenstein and Campos-Ortega 1984). Moreover, availability of an apparently complete description of the development of the NB array, which does not vary be- 
tween segments, allows us to unequivocally identify not only each NB but also some of their GMC progeny. Unlike the grasshopper (Bate 1976), the NB lineages in Drosophila are not topologically distinct, making the acquisition of lineage relationships difficult. The recent success of Technau and colleagues in adapting the cell transplantation and the DiI labeling techniques for tracing terminal cell lineages in Drosophila (Udolph et al. 1993; Bossing and Technau 1994; Prokop and Technau 1994) will largely overcome this difficulty. However, at present, the only published lineage information is on NB1-1 and NB4-2.

A number of novel genes as well as some known segmentation genes have been shown to play a role in the specification of CNS neural cell fate (for review, see Doe 1992a; Jimenez and Modolell 1993). However, much of the limited information on cell fate specification during the development of the Drosophila embryonic CNS has come from the study of genes that affect the early part of the NB4-2 lineage. It is known that the first GMC (designated GMC4-2a, under the nomenclature proposed by Doe 1992b/ derived from this NB divides to produce the RP2 motoneuron as well as a sibling cell (Doe 1992b; also see Fig. 1). The secreted wingless $(w g)$ gene product has been shown to be required in a cell nonautonomous manner for the specification/formation of NB4-2 (as well as six other NBs; Chu-LaGraff and Doe 1993). Additionally, the pair-rule homeo box genes fushi tarazu (ftz) and even-skipped (eve), both of which are expressed in GMC4-2a and the RP2 neuron, appear to be required for the formation of a correctly specified RP2 motoneuron

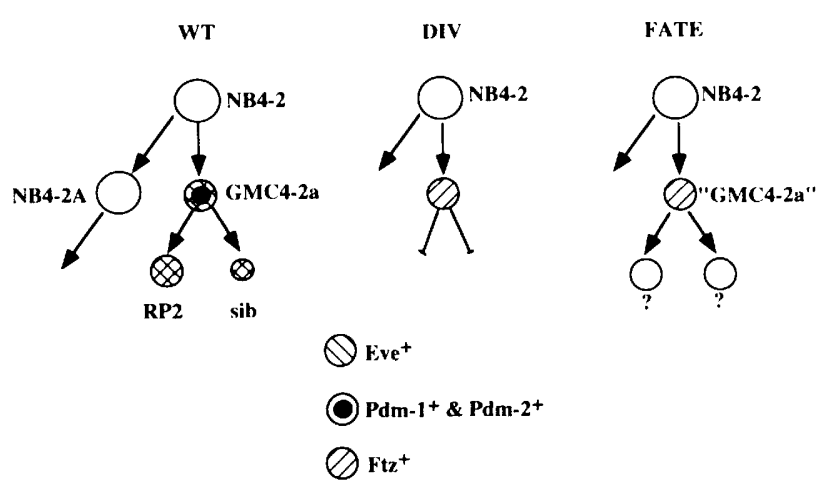

Figure 1. Possible roles of $p d m-1$ and $p d m-2$ in the NB4-2 lineage. In wild-type (WT) embryos GMC4-2a, the first GMC, divides to produce the RP2 motoneuron and its sibling cell. The Eve protein is expressed in GMC4-2a and its progeny, although the expression in the sibling cell is transient. Both Pdm-2 and Pdm-1 proteins accumulate to high levels only in GMC4-2a. If $p d m-1$ and $p d m-2$ act to positively regulate GMC4-2a cell division (DIV), we might expect the absence or decrease in number of RP2 neurons in mutant animals to be caused by a block in GMC4-2a cell division. On the other hand, if $p d m-1$ and $p d m-2$ act to specify GMC4-2a cell fate (FATE), limiting $p d m-1$ and $p d m-2$ function would cause GMC4-2a to adopt an aberrant cell fate; it might undergo cell division but not produce a mature (Eve expressing) RP2 neuron. These possibilities need not be mutually exclusive.
(Doe et al. 1988a,b). However it is not clear at this point whether $f t z$ and eve act at the level of GMC4-2a or the RP2 neuron. ftz acts upstream of $e v e$, and in the absence of $f t z$ function in the CNS Eve protein is not expressed in the NB4-2 lineage. The gene prospero (pros; Doe et al. 1991; Vaessin et al. 1991) is expressed in most if not all GMC-1 cells, including GMC4-2a. Total loss of pros function affects the fate of many CNS neurons including that of the RP2 motoneuron.

We and others (Billin et al. 1991; Dick et al. 1991; Lloyd and Sakonju 1991) have previously cloned a pair of closely linked POU domain genes $p d m-1$ and $p d m-2$, which encode proteins that show high degrees of identity to the mammalian POU proteins (Herr et al. 1988) Oct-1 and Oct-2. $p d m-1$ and $p d m-2$ show very similar and overlapping expression patterns. We have shown that within the early part of the NB4-2 lineage Pdm-2 protein accumulates to a high level only in GMC4-2a; our previous findings indicate that the misexpression of $p d m-2$ in the postmitotic progeny of GMC4-2a causes these cells to undergo another round of cell division (Yang et al. 1993), resulting ultimately in the duplication of the RP2 motoneuron and its sibling cell. These observations suggest, but do not allow, us to distinguish between two possible roles for $p d m-2$ (see Fig. 1). pdm-2 may act to specify the fate of GMC4-2a, and its misexpression causes the postmitotic daughter cells to both adopt the identity of GMC4-2a, thereby duplicating the GMC4-2a lineage. In this scenario, one might expect that the loss of $p d m-2$ function to cause GMC4-2a to adopt an aberrant cell identity. Alternatively, $p d m-2$ might normally act to positively regulate GMC4-2a cell division, and its misexpression merely causes the postmitotic daughter cells to undergo another round of cell division; in this case, one might expect the loss of $p d m-2$ function to cause a block in GMC4-2a cell division. These possibilities are not mutually exclusive. In addition, Bhat and Schedl (1994), by ectopically expressing a putative dominant negative $p d m-2$ transgene, obtained results consistent with a role for $p d m-2$ in the specification of GMC4-2a. However, interpretations based on data derived from ectopic expression and dominant negative approaches need to be viewed with care, particularly in view of the fact that at least two other POU domain genes are expressed in the CNS (Johnson and Hirsch 1990; Treacy et al. $1991)$.

Here, we report the isolation and analysis of a collection of mutations in $p d m-2$ and $p d m-1$. Our results prove that both of these genes contribute toward the development of a full complement of mature RP2 neurons, evidently by being expressed in and acting on GMC4-2a, the RP2 progenitor cell. Moreover, we resolve two important unanswered questions: (1) We show that $p d m-2$ and $p d m-1$ act to specify GMC4-2a cell identity and not merely act to positively regulate GMC4-2a cell division; (2) we demonstrate that the expression pattern of these two closely linked and structurally related genes show complete overlap within the NB4-2 lineage in the embryonic CNS, and this reflects an overlap in function. Finally, we show that within the hierarchy of genes ex- 
pressed in GMC4-2a, $p d m-1$ and $p d m-2$ lie downstream of pros and $f t z$ and upstream of eve.

\section{Results}

\section{Isolation of mutations affecting pdm-2 and pdm-1}

We have adopted two strategies to isolate mutations that affect the two Drosophila POU genes located at cytological position 33F1-3. First, by mobilizing a closely linked P element, $P\left[G R 801, w^{+}\right]$at position 34A5-6, and molecularly screening for local transpositions, we obtained two independent P-element insertions in the 5 '-flanking region of $p d m-2$, one of which $(P[1602])$ inserted at $30 \mathrm{bp}$ upstream of the $p d m-2$ transcription start site (Fig. 2; see Materials and methods). Additional alleles that affect $p d m-2$ or both $p d m-1$ and $p d m-2$ were obtained by imprecise excision or irradiation of $P[1602$ ] [see Materials and methods|. A summary of the mutant alleles analyzed in this paper and lesions associated with them is shown in Figure 2.

Additionally, we have used ethyl methane sulfonate (EMS) mutagenesis (Materials and methods; see Ashburner 1989 ) to isolate mutations that affect $p d m-1$ and $p d m-2$ function. To isolate putative $p d m-2$ mutations we generated alleles that map between cytological positions 33F1-3 and 34A1-2 by identifying mutations that caused lethality when heterozygous over a large deficiency, $D f(2 L)$ prd1.7, which deletes both $p d m-1$ and $p d m-2$, but were viable when heterozygous with another deficiency, $D f(2 L)$ Prl, which abolishes pdm-1 but not $p d m-2$ function in the embryo (see Fig. 2 and legend). Among these lethal alleles, two mutants, $p d m-2^{E 45}$ and $p d m-2^{E 46}$, affect the formation of the RP2 motoneuron and were therefore considered candidate $p d m-2$ alleles. The genomic DNA sequencing of $p d m-2^{E 46}$ revealed a $\mathrm{C} \rightarrow \mathrm{T}$ transition that introduces a stop codon at residue

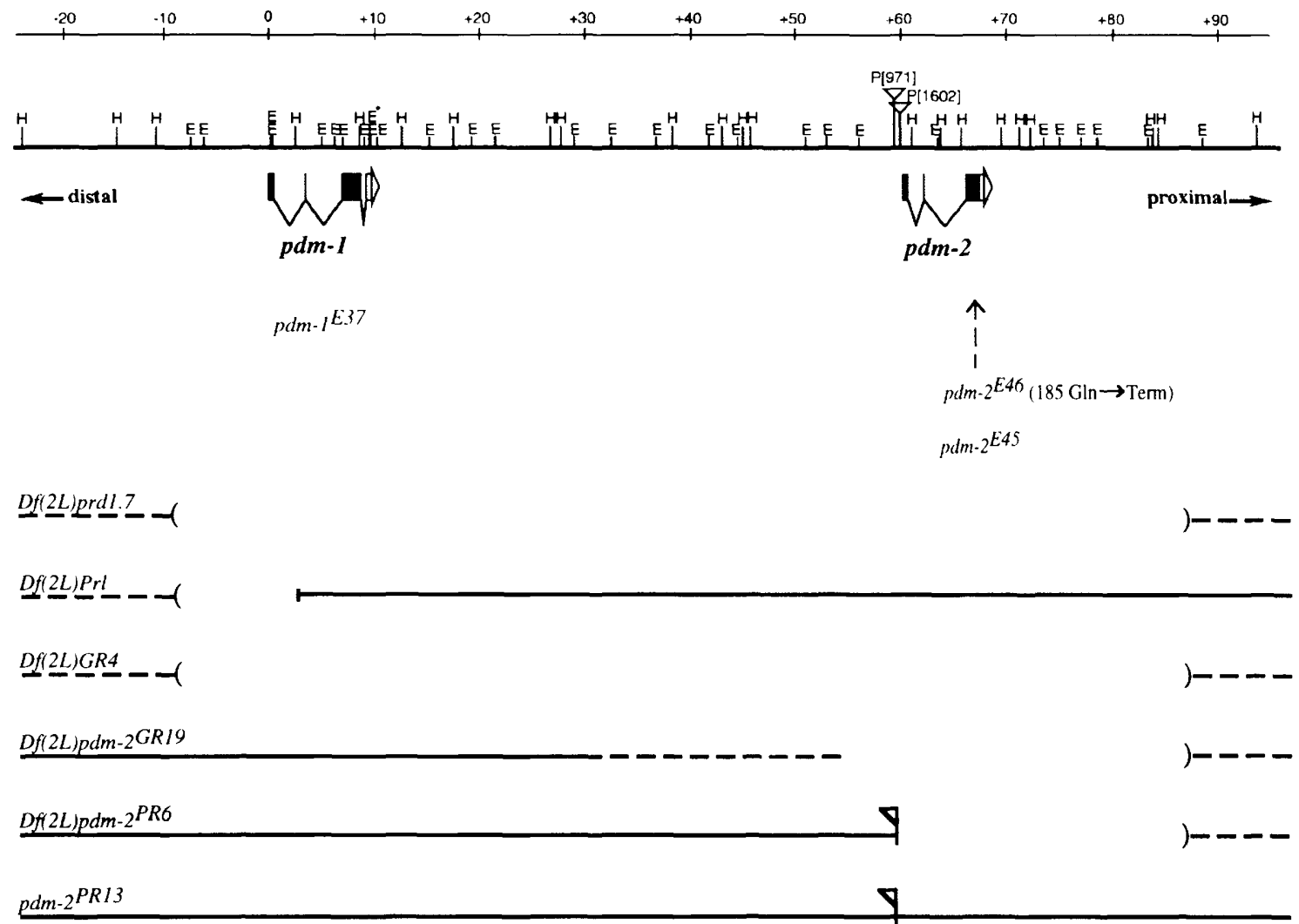

Figure 2. Mutations and deletions affecting $p d m-1$ and $p d m-2$. The $p d m-1$ and $p d m-2$ transcription units are located $\sim 50 \mathrm{~kb}$ apart. $P[1602]$ and $P / 971 /$ are $P\left[w^{+}\right]$insertions located $30 \mathrm{bp}$ and $\sim 200 \mathrm{bp}$, respectively, upstream of the pdm-2 transcription start site. $D f(2 L) p r d 1.7$ removes both $p d m-1$ and $p d m-2$, whereas $D f(2 L) P r l$ removes only the first exon of pdm-1 and leaves $p d m-2$ intact $[D f(2 L) P r l$ homozygous embryos are antigen minus for PDM-1]; both deficiencies also remove the segmentation gene paired. $D f(2 L) G R 4$ is a deletion removing both $p d m-1$ and $p d m-2$ but not paired. $D f(2 L) p d m-2^{P R \sigma}$ and $D f(2 L) p d m-2^{G R 19}$ both remove $p d m-2$ while leaving $p d m-1$ intact; their distal endpoints have not been mapped. $p d m-2^{P R 13}$ is an imprecise excision mutation obtained by mobilizing $P[1602]$, (see text). $p d m-2^{E 46}$ and $p d m-2^{E 45}$ are EMS-induced point mutations in $p d m-2 . p d m-2^{E 46}$ is caused by a mutation that introduces a premature chain termination at amino acid residue 185 of the Pdm-2 sequences, (see text and Materials and methods). $p d m-1^{E 37}$ is an EMS-induced antigen-minus point allele of $p d m-1$ (see Materials and methods). Parentheses mean that the endpoint is not mapped. The broken line in $D f(2 L) p d m-2^{G R 19}$ indicate the uncertainty in the mapping of the distal breakpoint. (H) HindIII; (E) EcoRI; the scale (top line) is in $\mathrm{kb}$. 
$185(\mathrm{G} \ln )$, predicting a truncated $\mathrm{Pdm}-2$ protein that lacks the POU (DNA binding) domain (see Materials and methods). To isolate $p d m-1$ mutations we examined all mutants with associated lethalities mapping within $D f(2 L) P r l . p d m-1^{E 37}$ was identified as a null allele of $p d m-1$. Embryos homozygous for $p d m-1^{E 37}$ do not express Pdm-1 protein but do express $p d m-1$ RNA, as judge by antibody staining and RNA in situ experiments (see Materials and methods).

Preexisting $D f(2 L) P r l$ and $D f(2 L)$ prd1.7 are large deficiencies that remove many genes including the segmentation gene paired, making attempts to interpret CNS development in animals homozygous or heterozygous for these two deficiencies problematic because of their gross segmentation defects. The new mutants used for the phenotypic analysis here are not complicated by epidermal defects.

The loss of pdm-2 function results in an incomplete loss of mature RP2 neurons

To determine the function of $p d m-2$, we focused our analysis on the early part of the cell lineage derived from NB4-2. NB4-2 divides to produce its first ganglion mother cell, GMC4-2a, in late stage 10 embryos. In late stage 11 embryos, GMC4-2a undergoes terminal divison to produce two daughter cells, recognizable by their Eve expression. One of the two cells retain Eve protein expression and, by stage 13, differentiates into the mature RP2 neuron with its characteristic position within the CNS, axon morphology, and marker gene expression (Eve, DPTP99A, and mAb 22C10). The other daughter of
GMC4-2a, the RP2 sibling cell, loses its Eve expression by the end of stage 13, and its ultimate fate is unknown. Our usage of the term mature RP2 neuron refers to an Eve protein expressing neuron at the characteristic RP2 position during stage 13 or later, which also stains with mAb 22C10 (Zipursky et al. 1984).

The effects of the removal of $p d m-2$ function on the formation of mature RP2 neurons was assessed by staining mutant embryos with an antibody (Frasch et al. 1986) that recognizes the Eve protein (anti-Eve). We examined five independently isolated $p d m-2$ alleles: $p d m-2^{P R 13}, p d m \cdot 2^{E 45}, p d m-2^{E 46}, D f(2 L) p d m-2^{p R 6}$ and, $D f(2 L) p d m-2^{G R 19}$. The weakest detectable homozygous phenotype is exhibited by $p d m-2^{P R 13}$ which carries an internally deleted derivative of $P[1602]$ and, hence, can be considered a point mutation for pdm-2. In homozygous $p d m-2^{p R 13}$ embryos, the number of hemisegments with a mature RP2 neuron is reduced to $99 \%$ (Table 1 ). The strongest homozygous phenotype is exhibited by $p d m-2^{E 46}$ embryos, where the number of hemisegments with a mature RP2 neuron is reduced further to $76 \%$ (Fig. 3; Table 1). The strongest allele, $p d m-2^{E 46}$, also fails to complement the other $p d m-2$ alleles for the "loss of $\mathrm{RP2}$ " phenotype. These results establish that $p d m-2$ contributes to the process required for the presence of mature RP2 neurons. To determine the phenotype of a null allele of $p d m-2, D f(2 L) p d m-2^{P} R 6$, homozygous embryos were examined. $D f(2 L) p d m-2^{\prime R 6}$ is a deletion that removes the entire $p d m-2$ transcription unit but leaves pdm-1 intact. In these embryos $90 \%$ of hemisegments showed a mature RP2 neuron (Fig. 3; Table 1). $D f(2 L) p d m-2^{\text {(iRly }}$ shows similar properties to $D f(2 L) p d m-2^{l P R}$ (data not shown). The incomplete expressivity of the loss of RP2 phenotype in animals totally

Table 1. Quantitation of the phenotype of mutant combinations

\begin{tabular}{|c|c|c|c|c|c|c|c|}
\hline & $\begin{array}{l}\text { Wild type } \\
\left|p d m-1^{+} p d m-2^{+}\right| \\
|\%|\end{array}$ & $\begin{array}{l}p d m-1^{E, 37} \\
\left|p d m-1 \quad p d m-2^{+}\right| \\
|\%|\end{array}$ & $\begin{array}{l}p d m-2^{\prime \prime k 1.3} \\
|p d m-1 \cdot p d m-2| \\
|\%|\end{array}$ & $\begin{array}{l}\text { Df(2L)pdm-2 } 2^{\prime \prime K} \\
\left|p d m-1^{+} p d m-2^{-}\right| \\
|\%|\end{array}$ & $\begin{array}{l}p d m-2^{E 46} \\
\left.\mid p d m-1^{\prime} p d m-2^{\prime}\right] \\
|\%|\end{array}$ & $\begin{array}{l}D f(2 L) G R 4 \\
\left\{p d m-1^{-} p d m-2^{-} \mid\right. \\
|\%|\end{array}$ & $\begin{array}{l}\text { Df2Llprd1.7 } \\
{\left[p d m-1^{-} p d m-2^{-} \mid\right.} \\
|\%|\end{array}$ \\
\hline $\begin{array}{l}p d m-1^{E, 37} \\
\left|p d m-1 \quad p d m-2^{\prime}\right|\end{array}$ & $\begin{array}{l}100 \\
(100)\end{array}$ & $\begin{array}{c}99.1 \\
\text { (N.D.) }\end{array}$ & N.D. & N.D. & N.D. & - & - \\
\hline $\begin{array}{l}p d m-2^{E 4.5} \\
p d m-1^{+} p d m-2^{-} \mid\end{array}$ & N.D. & N.D. & N.D. & N.D. & $\begin{array}{l}95.0 \\
\text { (N.D.) }\end{array}$ & N.D. & $\begin{array}{c}48.1 \\
\{87.3)\end{array}$ \\
\hline $\begin{array}{l}p d m-2^{P R 13} \\
{\left[\mathrm{pdm}-1^{+} p d m-2^{-}\right]}\end{array}$ & N.D. & N.D. & $\begin{array}{c}98.6 \\
\text { (N.D.) }\end{array}$ & - & - & - & - \\
\hline $\begin{array}{l}D f\left(2 L \mid p d m-2^{p R 6}\right. \\
{\left[p d m-1^{+} p d m-2^{-}\right]}\end{array}$ & N.D. & N.D. & N.D. & $\begin{array}{c}90.0 \\
\{93.0\}\end{array}$ & - & - & - \\
\hline $\begin{array}{l}p d m-2^{E 46} \\
{\left[p d m-1^{+} p d m-2^{-}\right]}\end{array}$ & $\begin{array}{c}100 \\
(100)\end{array}$ & N.D. & $\begin{array}{c}92.5 \\
\text { (N.D.) }\end{array}$ & $\begin{array}{c}80.0 \\
\text { (N.D.) }\end{array}$ & $\begin{array}{l}75.8 \\
\{91.8\}\end{array}$ & - & - \\
\hline $\begin{array}{l}D f(2 L) P r l \\
{\left[p d m-1^{-} p d m-2^{+}\right]}\end{array}$ & N.D. & N.D. & N.D. & N.D. & N.D. & $\begin{array}{c}71.3 \\
(79.3)\end{array}$ & N.D. \\
\hline $\begin{array}{l}D f(2 L \mid G R 4 \\
{\left[p d m-1^{-} p d m-2^{-}\right]}\end{array}$ & $\begin{array}{c}100 \\
\{100\}\end{array}$ & $\begin{array}{c}69.8 \\
(80.8)\end{array}$ & $\begin{array}{c}19.7 \\
\text { (N.D.) }\end{array}$ & $\begin{array}{c}6.8 \\
\text { (N.D.) }\end{array}$ & $\begin{array}{c}1.3 \\
(15.7)\end{array}$ & $\begin{array}{c}0 \\
\text { (0) }\end{array}$ & - \\
\hline Df(2L)prd1.7 & 100 & 72.3 & 12.7 & 2.3 & 0 & 0 & N.D. \\
\hline$\left[p d m-1^{-} p d m-2^{-}\right]$ & $\{100\}$ & (N.D.) & $(60.2)$ & $(8.5)$ & $(12.2)$ & $(0)$ & \\
\hline
\end{tabular}

The frequency of mature Eve-expressing RP2 neurons were assessed from anti-Eve-stained stage 15 and 16 embryos. The frequency of Eve-expressing GMC4-2a cells and/or their Eve-expressing postmitotic progeny were assessed by scoring anti-Eve-stained late stage 11 embryos. Each position represents a particular genotype; the percentage of hemisegments showing mature RP2 neurons for animals of that genotype is given as the top number without parenthesis; the percentage of hemisegments containing Eve-expressing GMC4-2a cells or Eve-expressing postmitotic progeny of GMC4-2a cells is given as the bottom number within parenthesis. A minimum of 320 hemisegments were scored for each genotype. For most genotypes, 440 hemisegments were scored. (N.D.) Not determined. 


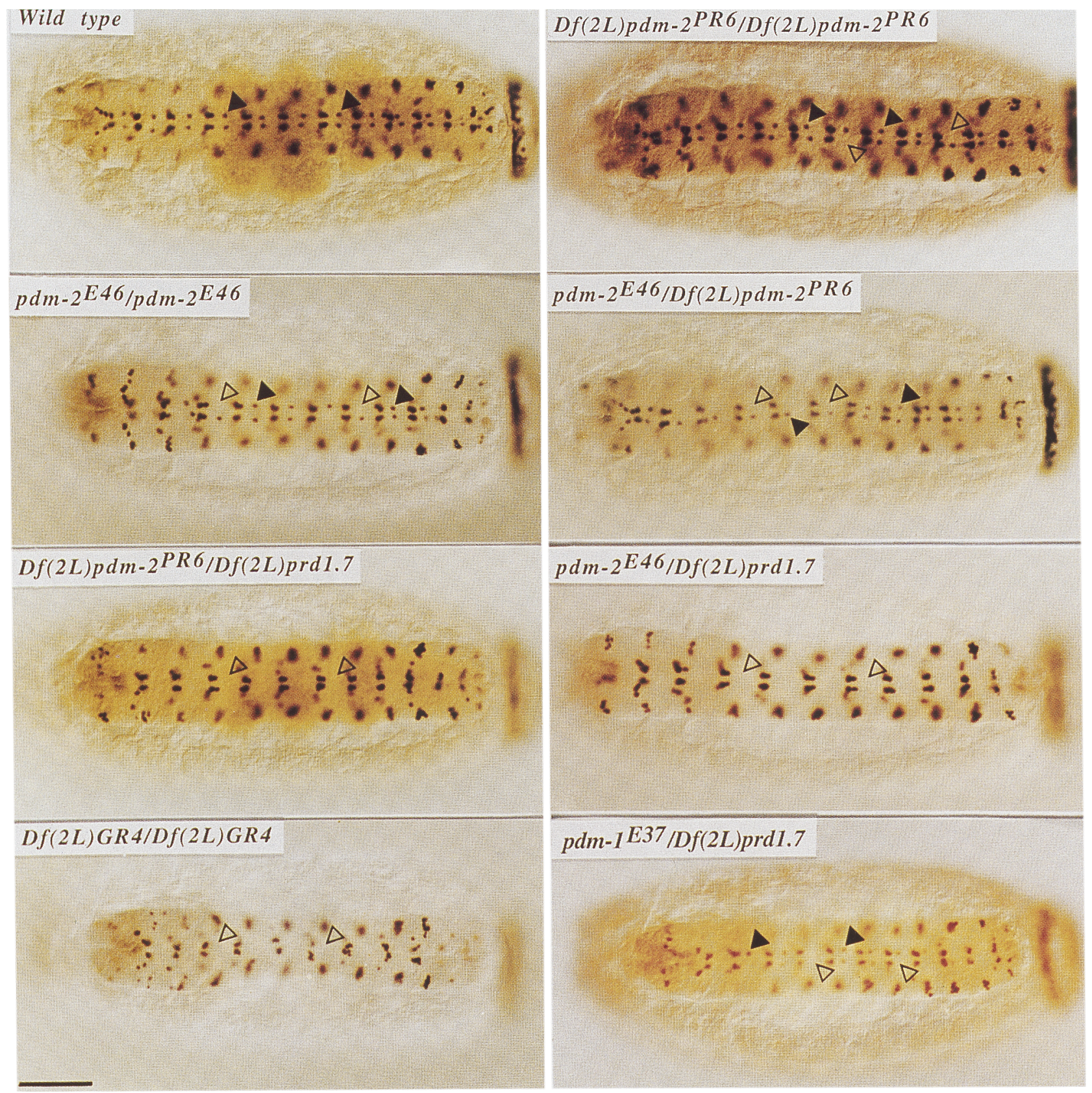

Figure 3. The effect of various mutant genotypes on the formation of mature RP2 neurons. Whole mounts of stage 16 embryos of various genotypes have been stained with anti-Eve (see Materials and methods). These micrographs show representative embryos. For quantitation, see Table 1. All panels show ventral views of the CNS. The presence of RP2 neurons is indicated by solid arrowheads; the absence of RP2 neurons is indicated by open arrowheads. The various genotypes examined are indicated in each panel. Anterior is toward the left. Bar, $50 \mu \mathrm{m}$.

deficient for $p d m-2$ function indicates that $p d m-2$ is involved but is not the only player in the process.

That the Pdm-2 protein might function in a common regulatory pathway with other putative players in generating mature RP2 neurons is suggested by the behavior of the $p d m-2^{E 46}$ allele. As indicated above, $p d m-2^{E 46}$ homozygous embryos show a more severe mutant pheno- type than that caused by $p d m-2$ null alleles. Moreover, pdm- $2^{E 46} / D f(2 L) p d m-2^{P R 6}$ embryos also show a more severe phenotype, with only $80 \%$ of hemisegments with a mature RP2 neuron (Fig. 3; Table 1). Control embryos that retain one wild-type copy of $p d m-2\left(p d m-2^{E 46} /+\right)$ show no loss of mature RP2 neurons (Table 1). Thus, $p d m-2^{E 46}$ exhibits a higher expressivity of mutant phe- 
notype than the null alleles of $p d m-2$. Together, these results indicate that $p d m-2^{E 46}$ has antimorphic properties, suggesting that the truncated $\mathrm{Pdm}-2$ protein (see previous section) encoded by this allele may interfere with the activity of another player involved in the development of mature RP2 neurons.

$\mathrm{pdm}-1$ is also involved in the genesis of mature RP2 motoneurons but plays a quantitatively less

important role than $\mathrm{pdm}-2$

What are the other players acting on the NB4-2 lineage to form RP2 neurons? One likely candidate is $p d m-1$, because of its similarity in protein structure and expression pattern (see next section) to $p d m-2$. To demonstrate directly the involvement of $p d m-1$ in the formation of mature RP2 neurons, we analyzed the phenotype associated with $p d m-1^{E 37}$ (see Table 1), an EMS-induced, antigen-minus allele of $p d m-1$ (see Materials and methods). The proportion of hemisegments with mature RP2 neurons is reduced in pdm-1 ${ }^{E 37}$ homozygous $(99 \%)$ and $p d m-1^{E 37} / D f(2 L) p r d 1.7(72 \%$, also see Fig. 3$)$ or $p d m-1^{E 37} / D f(2 L) G R 4$ embryos $(70 \%)$, compared with wild-type and $+/ D f(2 L)$ prd1.7 embryos $(100 \%)$. Therefore, like $p d m-2, p d m-1$ also contributes toward the genesis of RP2 neurons.

A comparison of mutant phenotypes suggests that $p d m-1$ and $p d m-2$ do not contribute equally to the formation of RP2 neurons. Animals homozygous for $p d m$ $1^{E 37}$ show a weaker phenotype than $p d m-2^{l} R 6 / p d m-2^{P R 6}$ animals, which are homozygous null for $p d m-2199 \%$ vs. $90 \%$ of hemisegments with RP2; see Table 1). Similarly, pdm-1 ${ }^{E 37} / D f(2 L)$ prd1.7 (72\%) and $D f(2 L) \operatorname{Prl} / D f(2 L) G R 4$ $(71 \%)$ embryos show weaker phenotypes than $\left.\mathrm{pdm}-2^{P R O}\right)$ Df(2L)prd1.7 (2\% of hemisegments with RP2; see Table 1). Because all of these comparisons are done between a $p d m-2$ null allele $\left(p d m-2^{P R o}\right)$ and two $p d m-1$ alleles that are likely to be null alleles $\left[p d m-1^{E .37}\right.$ and $D f(2 L) P r l$ homozygous embryos are antigen-minus for $\mathrm{Pdm}-1$, these data indicate that $p d m-1$ plays a quantitatively less important role than $p d m-2$.

That $p d m-1$ and $p d m-2$ play functionally overlapping roles is suggested further by the results shown in Figure 3 and Table 1 . In contrast to animals that lack $p d m-2$ but retain both copies of $p d m-1$, embryos that lack $p d m-2$ and one copy of $p d m-1$ show nearly complete loss of mature RP2 neurons. For instance, $p d m-2^{P R 13}$ / $D f(2 L) p r d 1.7$ embryos produce mature RP2 neurons in only $13 \%$ of their hemisegments (Table 1). Embryos heterozygous for a null allele of $p d m-2, D f(2 L) p d m-2^{p R \sigma}$, over $D f(2 L)$ prd1.7 show a more severe phenotype than that exhibited by $p d m-2^{P R 6}$ homozygotes, producing mature RP2 neurons in only $2 \%$ of their hemisegments (Fig. 3 ; Table 1). Mature RP2 neurons were totally absent in embryos that are $p d m-2^{E 46} / D f(2 L)$ prd1.7 (Fig. 3; Table 1). Very similar phenotypes are seen (Table 1) when these $p d m-2$ alleles are placed over $D f(2 L) G R 4$ (another deficiency chromosome that removes both $p d m-1$ and $p d m$ 2). Finally, embryos deficient for both $p d m-1$ and $p d m-2$, $D f(2 L) G R 4$ homozygotes, and $D f(2 L) G R 4 / D f(2 L)$ prd1.7 heterozygotes totally lack mature RP2 neurons (Fig. 3; Table 1). As expected, control embryos with the genotype $+/ D f(2 L)$ prd1.7 show RP2 neurons in all hemisegments (Table 1). These results suggest that in addition to $p d m-2$, other genes lying within the region deleted by $D f(2 L) p r d 1.7$ and $D f(2 L) G R 4$ is supplying an overlapping function in the process of making RP2 neurons.

However, $D f(2 L) p r d 1.7$ [and $D f(2 L) G R 4$ ] delete other genes in addition to $p d m-1$ and $p d m-2$. To demonstrate that loss of one copy of $p d m-1$ is responsible lat least in part) for the enhancement of the mutant phenotype, we wanted to determine whether over-expression of the Pdm-l protein [from a transgene, HSpdm-1, in which a full-length $p d m-1$ cDNA is driven by a HSP70 promoter; see Materials and methods], can restore at least some of the mature RP2 motoneurons in pdm- $2^{E 46} / D f(2 L) p r d 1.7$ embryos in which mature RP2 motoneurons are not made. Our results demonstrate that this is the case (Fig. 4 , cf. b and $c_{\text {; }}$ see quantitation). Whereas $p d m-2^{E 46}$ / $D f(2 L)$ prd1.7 embryos do not make any mature Eve expressing RP2 motoneurons, overexpression of $p d m-1$ in pdm-2 $2^{E 46} / D f(2 L) p r d 1.7 ; H S p d m-1 /+$ embryos restores RP2 motoneurons to a significant proportion $(14 \%)$ of the hemisegments. [We believe that the low level of restoration of RP2 neurons by overexpressing Pdm-1 is attributable, at least in part, to technical reasons /see Materials and methods).] Although these data do not rule out the potential contribution of yet another gene, they do indicate that $p d m-1$ and $p d m-2$ functionally overlap in the genesis of mature RP2 neurons.

\section{Pdm-1 and Pdm-2 are coexpressed in GMC4-2a}

Because $p d m-1$ and $p d m-2$ apparently overlap functionally, we wanted to determine whether these genes are coexpressed and can provide functions in the same cells within the CNS. Fusion proteins containing nonconserved regions of the predicted Pdm-1 and Pdm-2 proteins (see Materials and methods) were used to generate polyclonal serum. The specificity of the anti-Pdm-2 antibody has been described previously (Yang et al. 1993). That the anti-Pdm-1 serum specifically recognizes its gene product is demonstrated by the fact that (1) the protein expression patterns parallel the RNA expression pattern, and (2) we see no staining in animals deficient for $p d m-1$ (data not shown). The stainings observed with both antibodies are nuclear, as would be expected for proteins containing putative DNA-binding motifs.

The expression patterns of the Pdm-1 and Pdm-2 proteins during the early stages of the developing CNS are identical; it is a highly dynamic pattern that includes approximately half of the NBs and several GMCs (S.L. Yeo, unpubl.). We have shown previously that GMC4-2a expresses Pdm-2 protein by double labeling with antiEve and anti-Pdm-2 (Yang et al. 1993). Here, the expression of Pdm-1 and Pdm-2 proteins was assessed by double labeling with both anti-Pdm-1 and anti-Pdm-2 antibodies and using confocal microscopy /see Materials and methods|. In stage 11 embryos, during the segregation of the SIV NBs (see Doe 1992b), GMC4-2a accumulates 


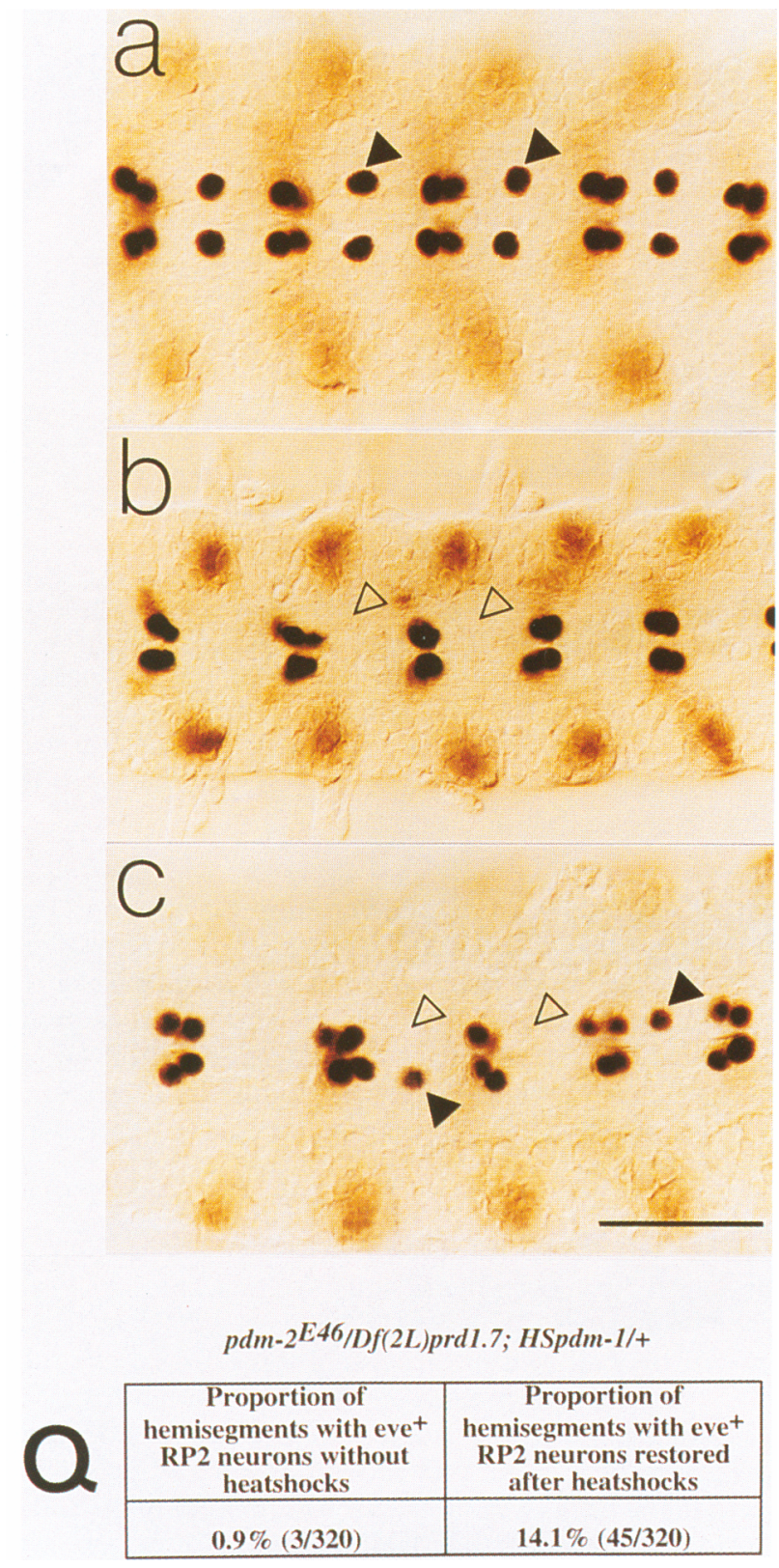

Figure 4. Overexpression of $p d m-1$ can restore mature RP2 neurons to mutant embryos. Dorsal views of dissected stage 16 embryonic CNS stained with anti-Eve are shown. $\{a \mid$ Wild-type; $(b)$ an embryo of the genotype $p d m-2^{E 46} / D f(2 L) p r d 1.7 ; H S p d m$ $1 /+$ (carrying one copy of the HSpdm-1 transgene, see text), without heat shock; $(c)$ a $p d m-2^{E 46} / D f(2 L) p r d 1.7 ; H S p d m-1 /+$ embryo that was subjected to heat shock (see Materials and methods) showing partial restoration of mature RP2 neurons. Presence of RP2 neurons is indicated by solid arrowheads and open arrowheads indicate the absence of RP2 neurons. Anterior is toward the left. Bar, $25 \mu \mathrm{m}$. Quantitations are given in Q.

high levels of both Pdm-1 and Pdm- 2 proteins in its nucleus (Fig. 5, arrow). In contrast, neither Pdm-1 nor Pdm-2 protein is detected at appreciable levels in NB4-2 (prior to its first division) or in the mature progeny of
GMC4-2a (not shown). Hence, the coexpression of $p d m-1$ and $p d m-2$ in GMC4-2a strongly suggests that they both function in this cell, explaining the functional overlap of $p d m-1$ and $p d m-2$.

\section{pdm- 1 and pdm-2 are not required for the birth of GMC4-2a}

In mutant animals in which mature RP2 neurons fail to be produced, GMC4-2a cells are nevertheless born. For instance, in animals deficient for both $p d m-1$ and $p d m-2$, GMC4-2a cells are born and can be detected because they retain Ftz protein expression (Fig. 6f). Similarly in $p d m-2^{E 46} / D f(2 L) p r d 1.7$ embryos, which also do not produce mature Eve-expressing RP2 neurons, GMC4-2a cells are born and can be detected by anti-Pdm-1 staining (Fig. 6e). Hence, $p d m-1$ and $p d m-2$ are not required for the birth of GMC4-2a.

The failure of mutant embryos to produce mature RP2 neurons is attributable, at least in part, to GMC4-2a adopting an aberrant cell identity

Two possible models can explain why animals mutant for $p d m-1$ and $p d m-2$ fail to produce mature RP2 neurons. GMC4-2a may adopt an aberrant fate and produce daughters that cannot differentiate correctly; alternatively, GMC4-2a may fail to divide. These models are not mutually exclusive. To examine these possibilities, we followed the fate of GMC4-2a. In wild type animals, Eve is expressed in both GMC4-2a and its postmitotic progeny (Fig. 6a). In animals deficient for both $p d m-1$ and pdm-2, for example, Df(2L)GR4 homozygotes or $D f(2 L) G R 4 / D f(2 L)$ prd1.7 embryos, GMC4-2a cells are born (see previous section) but never express Eve, and mature RP2 neurons are never made (Fig. 6d; Table 1). In $p d m-2^{E 46} / D f(2 L) p r d 1.7$ embryos, which also do not produce mature RP2 neurons, GMC4-2a cells are also born; however, most GMC4-2a cells (88\%) fail to express Eve (Fig. 6c; Table 1). Hence as judged by the expression of Eve protein, the cell identity of GMC4-2a is altered in the mutant embryos. Nevertheless, the $12 \%$ of GMC4$2 \mathrm{a}$ that do as express Eve in the $p d m-2^{E 46} / D f(2 L) p r d 1.7$ embryos goes on and divide and produce two daughter cells that transiently express Eve (Fig. 6c; Table 1); yet, no mature RP2 neurons are ultimately formed. Therefore, the lack of mature RP2 neurons in these animals cannot be attributed solely to a block in GMC4-2a cell division, as in mutant animals, at least some GMC4-2a cells can divide. (In this context, it should be noted that in several other mutant combinations the frequency of Eve expression of GMC4-2a cells and postmitotic progeny of GMC4-2a cells far exceed the frequency of mature RP2 neurons (Table 1); hence, the observation that some mutant GMC4-2a cells can divide to produce progeny that do not ultimately develop into mature RP2 neurons is a general effect not limited soley to the $p d m-2^{E 46}$ / Df(2L)prd1.7 mutant combination.) Moreover, because Pdm-1 and Pdm-2 proteins accumulate to high levels only in GMC4-2a, and not in NB4-2 or in the progeny of 

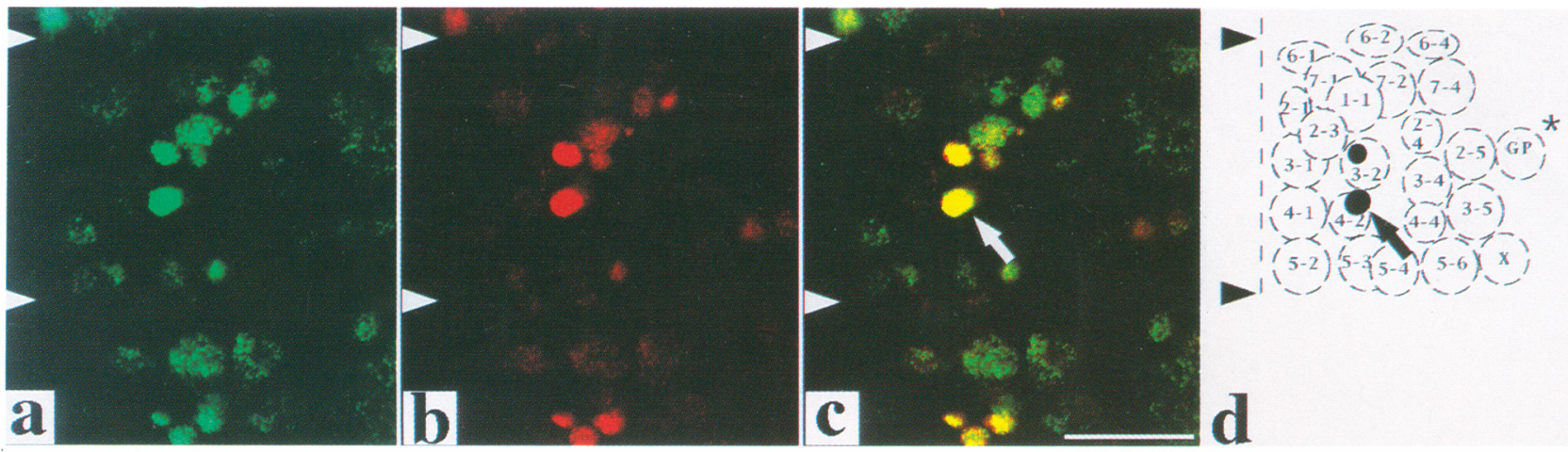

Figure 5. Coexpression of Pdm-1 and Pdm-2 proteins in GMC4-2a. $a, b$, and $c$ represent the same stage 11 embryo (undergoing SIV NB segregation), double stained with mouse anti-Pdm-1 (with FITC-conjugated secondary antibody) and rabbit anti-Pdm-2 (with biotinylated secondary antibody and avidine/Texas Red conjugate) viewed using confocal microscopy (see Materials and methods) at the plane of the GMCs. $(a)$ Expression of Pdm-1 protein in GMCs viewed through the green channel; $(b)$ expression of Pdm-2 protein viewed through the red channel; $(c)$ coexpression of both Pdm-1 and Pdm-2 proteins in the GMCs (yellow). Arrowheads are positioned at the midline and points to the parasegment grooves that delineate row five and row six NBs. The position of GMC4-2a is indicated (arrow). Bar; $25 \mu \mathrm{m}$. (d) A schematic showing the positions of the NBs. The positions of the two strongest expressing GMCs lying dorsal/lateral to NB4-2 and NB3-2 are indicated (O). The asterisk (*) indicates the position of the tracheal pits. (GP) The glioblast that gives rise to the longitudinal glia cells (Jacobs et al. 1989). The dashed line represents the midline. Anterior is toward the top.

GMC4-2a, the implication is that $p d m-1$ and $p d m-2$ are required to specify GMC4-2a cell identity. Whether or not they also act to positively regulate GMC4-2a cell division remains an unanswered question (see Discussion).

Within the hierarchy of genes expressed in GMC4-2a, $\mathrm{pdm}-1$ and pdm-2 lie downstream of pros and $\mathrm{ftz}$ but upstream of eve

The results presented so far have given an indication of where the POU genes lie within the hierarchy of genes expressed in GMC4-2a. In the absence of $p d m-1$ and $p d m-2$, Eve is not expressed in GMC4-2a (see Fig. 6d and previous section), suggesting that eve is positively regulated by and lies downstream of $p d m-1$ and $p d m-2$. In addition, we have shown that in the absence of $p d m-1$ and $p d m-2, \mathrm{Ftz}$ is still expressed in GMC4-2a (see Fig. $6 f$ and abovel, consistent with the notion that $p d m-1$ and $p d m-2$ lie downstream of $f t z$. To confirm and expand on the suggested hierarchical relationships, we examined the expression of Pdm-1 and Pdm-2 in embryos mutant for eve, ftz, and pros. In pros ${ }^{-}$embryos, Pdm-2 land Pdm-1; data not shown) protein is not expressed in GMC4-2a (Fig. 7c). Total loss of function of eve or $f t z$ causes segmentation defects that preclude interpretations of what might be occurring within the CNS. To circumvent this problem, we used a temperature-sensitive allele of $e v e$, $e v e^{I D I 9}$, which allowed us to turn off eve function after its requirement for normal epidermal development had been fulfilled (Materials and methods; see Doe et al. 1988b). Similarly, we used a strain, $f t z K .6$; $f t z^{-}$, carrying a modified $f t z$ gene that expresses $f t z$ in the epidermis and shows normal or nearly normal epidermal development but does not express $f t z$ in the CNS (Doe et al. 1988a). In embryos that are $f t z^{-}$in the CNS,
Pdm-2 (and Pdm-1; not shown) proteins are not expressed in GMC4-2a (Fig. 7b). In $e v e^{I D I 9}$ embryos in which Eve has been inactivated by a temperature shift following gastrulation, $\mathrm{Pdm}-2$ (and Pdm-1; not shown) are nevertheless expressed in GMC4-2a (Fig. 7d). Taken together, these data indicate the hierarchical relationships among the genes that are expressed in GMC4-2a (see Fig. 7e).

\section{Discussion}

Our results from the genetic and developmental analysis of $p d m-1$ and $p d m-2$ reveal the concerted roles of these genes in the cell fate specification of GMC4-2a and, ultimately, the development of the RP2 motoneuron. We report the isolation of a series of mutations affecting $p d m-1$ and $p d m-2$ function as well as a set of deletions that remove $p d m-2$ and $p d m-1$ either singly or in combination. In animals that lack all $p d m-2$ function, we observe a frequent failure to form a correctly specified RP2 motoneuron because its parental GMC4-2a fails to adopt a correct cell identity. This phenotype is not fully expressive because $p d m-1$ also contributes to the same process, and to observe a complete or nearly complete loss of function phenotype at least one copy of $p d m-1$ must be inactivated as well. Although both $p d m-1$ and $p d m-2$ are apparently involved in the specification of GMC4-2a, it appears that $p d m-2$ plays a quantitatively more major role. Mutant animals totally deficient for both $p d m-1$ and $p d m-2$ fail to produce any mature RP2 neurons. Our results indicate that their parental GMCs also fail to acquire their correct identity. In a mutant combination $\left[p d m-2^{E 46} / D f(2 L) p r d 1.7\right]$ in which the $p d m-1$ and $p d m-2$ functions are limiting such that no mature RP2 neurons are produced, some GMC4-2a cells can nevertheless divide, although their daughter cells never develop into mature RP2 neurons. Hence, the fail- 


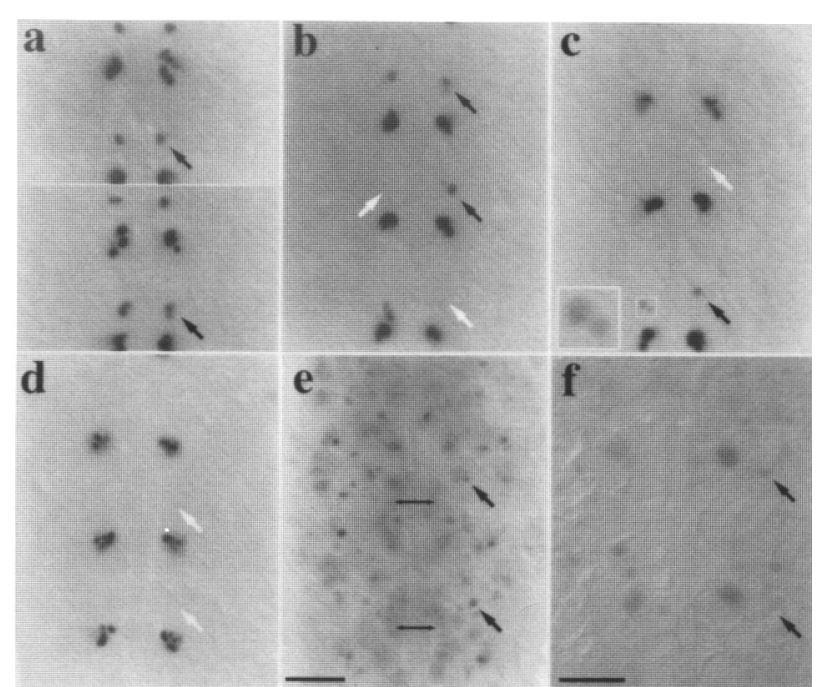

Figure 6. The fate of GMC4-2a in mutant embryos. $(a-d)$ Ventral views of three to four segments of representative stage 11 embryos stained with anti-Eve. Black arrows indicate the presence of Eve-expressing GMC4-2a cells, Eve-expressing dividing GMC4-2a cells or their Eve-expressing postmitotic cells. White arrows indicate the absence of Eve-expressing GMC4-2a cells or their Eve-expressing postmitotic progeny. (a) A wild-type embryo; (top) GMC4-2a cells expressing Eve protein (just before they divide); (bottom) Eve-expressing postmitotic progeny of GMC4-2a. (b) A $D f(2 L) p d m-2^{P R \sigma} / D f(2 L) p d m-2^{P R \sigma}$ embryo, showing the absence of Eve-expressing GMC4-2a cells or their Eve-expressing progeny from a proportion of the hemisegments (see Table 1 for quantitation). (c) A pdm-2 $2^{E 46} / D f(2 L)$ prd1.7 embryo showing only two hemisegments with Eve-expressing, dividing GMC4-2a lor Eve-expressing progeny derived from GMC4-2a). (Inset) An enlargement of a pair of Eve-expressing postmitotic progeny derived from GMC4-2a. (d) A Df(2L)GR4/ $D f(2 L) G R 4$ embryo. No Eve-expressing GMC4-2a or progeny cells are seen (white arrows) at this or any other time of embryonic development. (e) A stage $11 \mathrm{pdm}-2^{E 46} / D f(2 L) p r d 1.7 \mathrm{em}$ bryo stained with anti-Pdm-1. Pdm-1 protein-expressing GMC4-2a cellss are present in all hemisegments, two of which occupy the right focal plane and are indicated by black arrows. The positions of the parasegmental grooves, delineating row 5 and row $6 \mathrm{NBs}$, are indicated (double-headed arrows). GMC4-2a is located just dorsal or dorsal/lateral to NB4-2A and can be identified following staining with anti-Pdm-1 (see Materials and methods). (f) A late stage $10 D f(2 L) G R 4 / D f(2 L) G R 4$ embryo stained with anti-Ftz, showing the presence of $\mathrm{Ftz}$ expressing GMC4-2a cells (black arrows). Anterior is toward the top in all panels. Bar, $25 \mu \mathrm{m}$.

ure to produce mature RP2 neurons is not dependent on a block in GMC4-2a cell division per se. Our results indicate that $\mathrm{Pdm}-2$ and $\mathrm{Pdm}-1$ proteins are expressed in GMC4-2a and that $p d m-1$ and $p d m-2$ overlap functionally to specify GMC4-2a cell identity. It remains to be seen whether these genes also act to regulate GMC4-2a cell division.

pdm-1 and pdm-2 and cell fate specification

The cellular identity of any given NB appears to be dependent on its position of delamination from the ecto- derm (Doe and Goodman 1985). The unique identities of the NBs are manifested by their specific pattern of gene expression and by the characteristic and distinct lineages arising from each NB (Doe 1992b). Doe (1992a) has proposed that NB identity is determined by a set of NB identity genes. These genes constitute a combinatorial code and are expressed in a specific combination in each of the NBs to specify their identity and initiate a lineage. Each of the GMCs, in response to the inherited products of the NB identity genes, in turn, activates a specific combination of GMC identity genes to define the identity of that cell. Implicit to this model is the assumption that the identity of the GMC ultimately determines the identity of its two daughter neurons and/or glia cells.

Two of the best characterized genes whose loss of function result in neuronal cell fate changes are eve and $f t z$. On the basis of their phenotypes, it has been suggested that they might act as GMC identity genes (Doe et al. 1988a,b). However, because Eve and Ftz proteins are expressed both in the affected neuron as well as its progenitor GMC, it is not clear whether these genes act at the level of the GMC or the neuron. The $p d m-1$ and $p d m-2$ genes described here, as well as pros (Doe et al. 1991; Vaessin et al. 1991), appear to be GMC identity genes in the context of the model proposed by Doe (1992a). All three protein products appear to accumulate to high levels in the GMCs that give rise to the affected neurons but not in the neurons themselves. In the case of $p d m-1$ and $p d m-2$, we have shown that the neuronal cell fate change associated with their loss of function results as a consequence of a cell fate change at the level of the GMC.

Our data clearly indicate that eve lies downstream of $p d m-1$ and $p d m-2$ within the hierarchy of genes expressed in GMC4-2a, because in their absence Eve is never expressed in GMC4-2a. One point central to the interpretation of our data is the assumption that the failure to express Eve protein equates with an alteration in RP2 neuronal cell identity. This assumption is reasonable, as it has been shown previously (Doe et al. 1988b) that on the basis of axon morphology, the RP2 neuron adopts an aberrant cell fate under conditions of limiting eve function; therefore, eve is most likely required for a correct RP2 cell identity.

It is interesting to note that in various $p d m-1$ and $p d m-2$ mutant combinations, the expression of Eve in the GMC4-2a does not necessarily equate with the ultimate formation of a mature RP2 neuron. It is clear that in both $p d m-2^{E 46}$ homozygote and in $p d m-2^{E 46}$ / $D f(2 L)$ prd1.7 embryos, a certain fraction of Eve-expressing GMC4-2a cells do not ultimately give rise to a mature RP2 neuron, as the proportion of Eve-expressing GMC4-2a cells at stage 11 is invariably higher than the proportion of mature RP2 neurons seen at stage 13 or later (see Table 1). This observation may reflect the fact that genes other than eve are regulated by $p d m-1$ and $p d m-2$ and that eve expression alone is insufficient to confer a GMC4-2a cell identity.

In addition to GMC4-2a, pdm-1 and pdm-2 are expressed in many other cells within the CNS, in about 


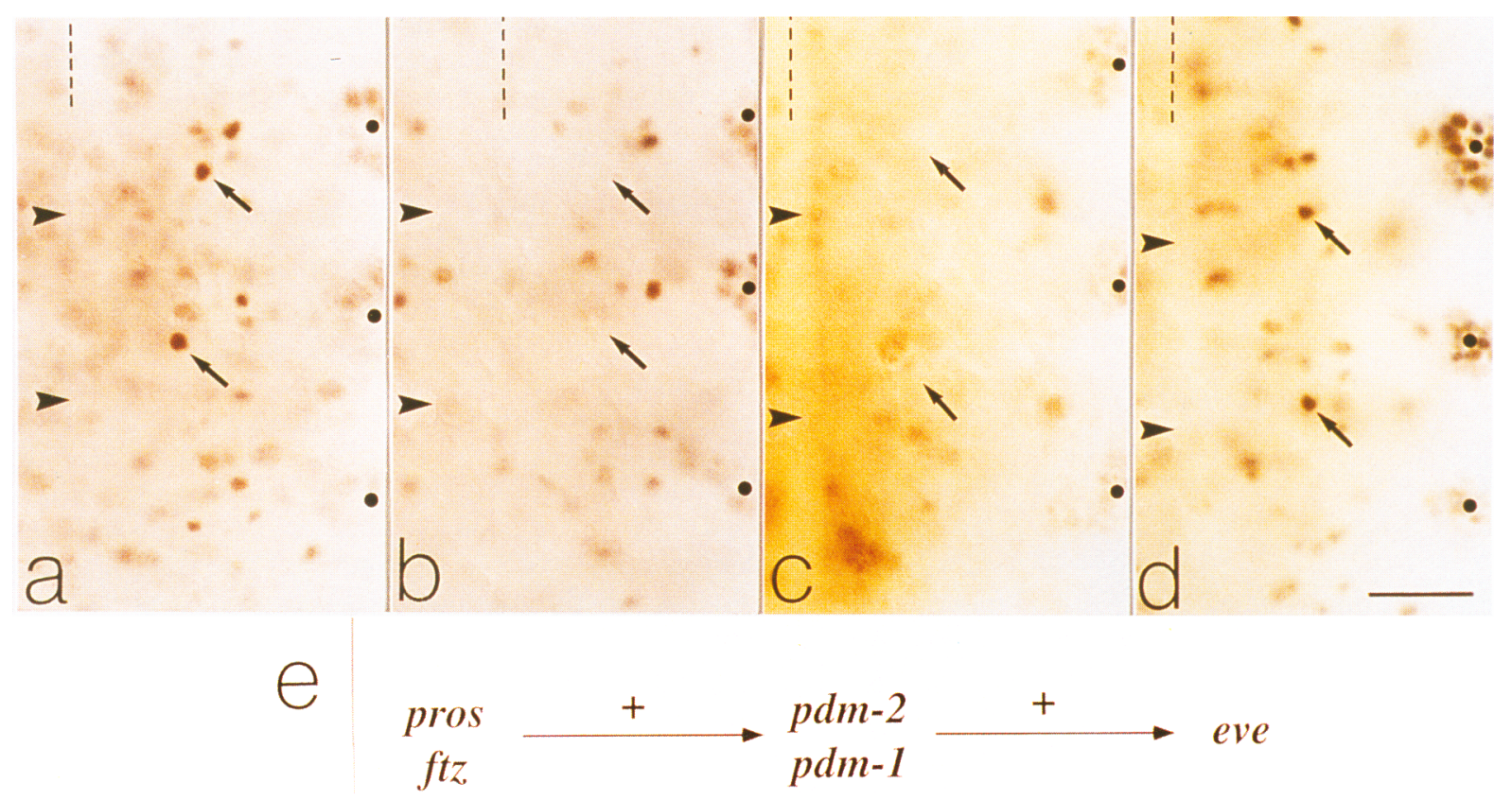

Figure 7. Hierarchical relationships among genes that are expressed in GMC4-2a. Stage 11 embryos mutant for $f t z$, pros, and eve were stained with anti-Pdm-2. Two hemisegments are shown. (a) A wild-type embryo; the expression of Pdm-2 protein in GMC4-2a cells is indicated (by arrows). (b) A homozygous $\mathrm{ftzK}$.6; $\mathrm{ftz}{ }^{-}$embryo; embryos of this genotype fail to express Ftz protein only in their CNS and show either normal or only mildly defective epidermal development (Doe et al. 1988a); GMC4-2a cells fail to express Pdm-2 protein in this mutant background as indicated by the arrows. (c) A homozygous pros ${ }^{17} /$ pros $^{17}$ embryo; $^{\text {pros }}{ }^{17}$ is a loss-of-function allele of prospero (see Doe et al. 1991); GMC4-2a cells of these embryos do not express Pdm-2 protein (indicated by arrows). (d) A homozygous $e v e^{I D I 9}$ embryo; $e v e^{I D I 9}$ encodes a temperature-sensitive Eve protein that is inactivated at the nonpermissive temperature; using this allele, one can inactivate eve function after its requirement for normal segmentation has been fulfilled (see Materials and methods; Doe et al. 1988b); Pdm-2 protein is expressed in GMC4-2a at the nonpermissive temperature (indicated by arrows). (e) A schematic showing the hierarchical relationships among the genes known to be expressed in GMC4-2a. Anterior is toward the top. Positions of the parasegmental grooves are indicated (arrowheads). Dashed lines indicate midline. (O) Tracheal pits. Bar, $25 \mu \mathrm{m}$.

half of the NBs and many GMCs. However, using an array of antibodies that mark subsets of CNS cell nuclei [e.g. anti-Ftz, anti-Engrailed (En), anti-Gooseberry] we have not detected obvious cell fate changes in animals deficient for both $p d m-1$ and $p d m-2$, other than those described here (data not shown). In each of the $p d m$ expressing cells in the embryonic CNS (before stage 13), $p d m-1$ and $p d m-2$ are coexpressed (S. Yeo, unpubl.), suggesting that they function together. We have demonstrated that this is the case for the NB4-2 lineage: Both $p d m-1$ and $p d m-2$ are required to specify the identity of GMC4-2a. Furthermore, we have shown that the pdm$2^{E 46}$ allele has dominant-negative properties. This suggests that the encoded, truncated Pdm-2 protein, without the DNA-binding domain, might interfere with the activity of the wild-type Pdm-1 protein. This interference could occur by direct interaction of the truncated protein to $\mathrm{Pdm}-1$, thereby reducing or inactivating Pdm-1 activity, or by sequestering another component of the transcriptional machinary in a nonproductive complex.

\section{Functional redundancy of pdm-1 and pdm-2}

There are many examples in several organisms where two (or more) genes encode identical or overlapping func- tions (e.g., cyclins) such that a phenotype is observed only when both genes are removed (for review, see Thomas 1993). In Drosophila, examples of structurally related, closely linked, gene pairs expressed in highly similar patterns include $\mathrm{BarH} 1$ and $\mathrm{BarH} 2$ (Hagashijima et al. 1992), en and invected (Poole et al. 1985; Coleman et al. 1987), gooseberry proximal and gooseberry distal (Baumgartner et al. 1987; Gutjahr et al. 1993), knirps and knirps-related (Rothe et al. 1989, 1992), and sloppy paired 1 and 2 (Grossniklaus et al. 1992; Cadigan et al. 1994). In the case of the gene pairs at the Bar and sloppy paired loci, a functional overlap has been demonstrated. For the rest of the examples, a functional role has been shown only for one member of the gene pair. $p d m-1$ and $p d m-2$ provide another example of a functionally overlapping Drosophila gene pair.

For the $p d m-1$ and $p d m-2$ gene pair, we have shown that the loss of $p d m-2$ function alone fails to affect normal development of the RP2 motoneuron in $90 \%$ of the hemisegments. Furthermore, we show that the loss of $p d m-1$ function alone has a less extreme phenotype than that of $p d m-2$ loss-of-function animals. Because a small deficiency removing both $p d m-1$ and $p d m-2$ results in a complete loss of all RP2 motoneurons, our results point to an overlap in the function of these two genes, at least with respect to the making of the RP2 motoneuron. In 
this context, it is interesting to note that the $p d m-2$ gene is dispensable. Animals homozygous for $p d m-2^{E 46}$ which give the strongest phenotype are fully viable; the surviving adults do not exhibit any obvious morphological defects. Lethality only occurs when it is heterozygous over deficiencies that remove both $p d m-1$ and $p d m-2$ [e.g., $D f(2 L) p r d 1.7$ or $D f(2 L) G R 4$ ] Similarly, $p d m-1$ is likely to be dispensable as long as two copies of $p d m-2$ are present. Thus, a full complement of RP2 neurons does not appear to be required, at least in laboratory fly cultures, for full viability. This, in turn, suggests that the selective pressure to maintain both the $p d m-1$ and $p d m-2$ genes for the purpose of specifying a complete set of RP2 motoneurons must be quite subtle or that these genes are selected for functions that are unique to each gene. In support of the latter possibility, we have found that $p d m-1$ and $p d m-2$ are expressed differentially in the embryonic gut and certain imaginal discs (S. Yeo, unpubl.).

\section{Do pdm-1 and pdm-2 regulate GMC4-2a cell division?}

Our results indicate that $p d m-1$ and $p d m-2$ act in an overlapping manner to specify GMC4-2a cell identity. Our data also indicate that in embryos with limiting pdm-1 and pdm-2 function (but not a total absence of both functions) some GMC4-2a cells can divide without producing mature RP2 neurons. Hence, the failure to make mature RP2 neurons does not depend on a block in GMC4-2a cell division per se. However, we are unable to follow the fate of GMC4-2a in embryos that are deleted for both $p d m-1$ and $p d m-2$ because of the lack of a suitable marker. Therefore, it is certainly possible that $p d m-1$ and $p d m-2$ effect GMC4-2a cell fate specification, as well as division, and that in the total absence of both functions, GMC4-2a not only acquires an aberrant identity but also fails to divide. We eagerly await developments in technology that will enable us to follow the fate of GMC4-2a in vivo and resolve this issue.

\section{Materials and methods}

\section{Standard molecular biology and Drosophila techniques}

Standard molecular biology and Drosophila laboratory techniques were performed according to Sambrook et al. (1989) and Ashburner (1989).

\section{Fly strains}

GR801, Df(2L)Prl/CyO, and Df(2L)prd1.7/CyO were obtained from the Tübingen and Bloomington Stock Centers. $f t z K .6$; $\mathrm{ftz}^{-}, \operatorname{pros}^{17}$, and $e v e^{I D I 9}$ stocks were obtained from Chris Doe (University of Illinois, Urbana).

\section{Mutagenesis by local transposition}

To obtain P-element insertions in or around the $p d m-1$ and pdm-2 genomic regions, we took advantage of the observations that $\mathrm{P}$ elements transpose to nearby sites at high frequency
(Tower et al. 1993; Zhang and Spradling 1993; Golic 1994). P/GR801, $\left.w^{+}\right]$, a P element carrying white ${ }^{+}\left(w^{+}\right)$as marker and located at cytological position 34A5-6, was mobilized using $\Delta 2-3$ as a genomic source of transposase (Robertson et al. 1988) in females with the genotype $w ; P\left[G R 801, w^{+}\right] /+; \Delta 2-3, \mathrm{Sb} /+$. A single copy of $P\left[G R 801, w^{+}\right]$gives its carriers dull red eye color. These females were crossed to $w ; \mathrm{CyO} / \mathrm{Sco}$ males, and candidates among $F_{1}$ progeny that carried an additional copy of locally transposed $\mathrm{P}$ element were identified by their bright eye color resulting from two copies of $w^{+}$. The frequency of presumed local transposition (the frequency of $F_{1}$ flies with two copies of $w^{+}$that segregate with the second chromosome) for $P / G R 801 /$ was $1.5 \%$. We established 515 independent lines from these candidates and screened for P elements that inserted into the genomic region of $p d m-1$ or $p d m-2$ gene in groups of 25 lines, in the following manner.

Single flies from 25 lines were pooled, and genomic DNA was isolated using a standard protocol. The genomic sequences flanking the insertion sites in each pool were amplified by inverse PCR as follows. Genomic DNA from each pool was digested with NdeII, which cuts at a site internal to the P $5^{\prime}$ terminal sequence in $P / G R 801 /$ and at an unknown site in the genomic DNA flanking each P-element insertion. Following heat inactivation of the restriction enzyme at $65^{\circ} \mathrm{C}$ for $15 \mathrm{~min}$, the DNA was diluted to $10 \mu \mathrm{g} / \mathrm{ml}$ in a $100-\mu l$ volume of $l \times$ ligase buffer and circularized by ligating for $4 \mathrm{hr}$ with 12 Weiss units of T4 DNA ligase (New England Biolabs). Polymerase chain reaction (PCR) was performed in two consecutive steps, with the following two pairs of nested primers that recognize the 5'-terminal sequence of the $\mathrm{P}$ element: Outer primer 1 , 5'-TCCAGTCACAGCTTTGCAGC; outer primer 2, 5' -GTGGGAGTACACAAACAGAG; inner primer 1, 5'-AAGTGTATACTTCGGTAAGC; inner primer 2, 5'-AAATGCGTCGTTTAGAGCAG. The first PCR was performed with $10 \mu \mathrm{l}$ of the ligation reaction, two outer primers and 2.5 units of Taq DNA polymerase (Boehringer Mannheim) in a total volume of $100 \mu \mathrm{l}$. The second PCR was performed like the first but with $1 \mu l$ of the first PCR mix and two inner primers. The second PCR was monitored by analyzing $10 \mu \mathrm{l}$ on a $1 \%$ agarose gel where multiple bands could be visualized. Ten mililiters of this complex PCR product was radiolabeled with ${ }^{32} \mathrm{P}$ by random priming (Stratagene Prime-It II Kit) and used to probe filters that contained EcoRI-digested $\lambda$ and cosmid genomic clones from the $p d m-1$ and $p d m-2$ region. Insertions in this region are represented in the complex probe and detected because the labeled flanking DNA recognizes the corresponding fragment in the genomic clone. As a control for the sensitivity of the method, we found it useful to include an additional mapped P-element insertion line in each pool and to include a genomic clone that contains that insertion site on the filters. Control experiments indicate that if needed, 100 lines at a time can be pooled and screened by this method. After identifying the pool that contained genomic DNA from an insertion in the $p d m-2$ region, members of the pool were screened individually by genomic Southern analysis to identify the mutant line. Among the 515 lines, we identified two P-element transpositions, $P[971]$ and $P$ [1602], which had inserted at $\sim 200$ and $30 \mathrm{bp}$, respectively, upstream of the $p d m-2$ transcription start site (Fig. 2)

\section{Mutagenesis by imprecise excision and yirradiation}

Additional mutations in the $p d m-1$ and $p d m-2$ region were generated by inducing imprecise excision or $\gamma$ irradiation of $P / 1602$, $\left.W^{+}\right]$. P-element excision was induced in males with the genotype, $w ; P\left[1602, w^{+}\right] P\left[G R 801, w^{+}\right] ; \Delta 2-3, \mathrm{Sb} /+$. These males were crossed to $w ; C y O / S c o$ females, and $F_{1}$ flies that had lost 
one copy of the $P$ elements were identified by their dull red eye color. Among 40 lines that had excised one copy of the P elements, 4 were identified by genomic Southern analysis as having lost genomic DNA flanking the $p$ (1602) insertion site or DNA internal to the $P$ element. We have genetically characterized two of these lines in this paper: $D f(2 L) p d m-2^{P R 6}$ has the entire $p d m-2$ transcribed region deleted and $p d m-2^{P R 13}$ has a deletion internal to $P[1602]$.

Mutations were also induced by irradiating $P\left(1602, w^{+}\right] / C y O$ males with 4000 rads from a ${ }^{137} \mathrm{Cs}$ source and crossing them to $w$; $\mathrm{CyO} / \mathrm{Sco}$ females. $\mathrm{F}_{1}$ flies carrying chromosomes that had lost $P\left[1602, w^{+}\right]$were identified by their eye color. We established nine lines with such mutations, most of which were associated with a deletion internal to $P[1602]$. Two of the lines, $D f(2 L) G R 4$ and $D f(2 L) p d m-2^{G R 19}$, had a deletion of both $p d m-1$ and $p d m-2$ or only $p d m-2$, respectively, as determined by genomic Southern analysis (Fig. 2) and have been genetically characterized in this paper.

\section{EMS mutagenesis}

EMS mutagenesis was performed according to Grigliatti (1986). Males with an isogenized wild-type second chromosome were fed $0.025 \mathrm{M}$ of EMS after a day of starvation. The mutagenized males were mated with $\mathrm{Gla} / \mathrm{CyO}$ virgins, and the males were removed after 5 days. Single $\mathrm{CyO}$ progeny were crossed to $D f(2 L) p r d 1.7 / C y O$, and males from vials that failed to yield non- $\mathrm{CyO}$ flies [because of recessive lethality in the region deleted in $D f(2 L) p r d 1.7$ l were retested by crossing to $D f(2 L) P r l /$ $\mathrm{CyO}$. For $p d m-2$ alleles, we looked for mutations that were lethal when heterozygous over $D f(2 L) p r d 1.7\left(p d m-1 \quad p d m-2^{-}\right)$ but were viable over $D f(2 L) P r I\left(p d m-1^{-} p d m-2^{+}\right)$; $D f(2 L) P r l$ homozygous embryos are antigen-minus for Pdm-1. In 20,000 mutagenized chromosomes we recovered 38 candidates that fulfilled these criteria. Embryos of these candidate chromosomes over $D f(2 L) p r d 1.7$ were stained with anti-Eve antibody to identify mutations that caused loss of RP2 motoneurons. Two of these mutants, $p d m-2^{E 45}$ and $p d m-2^{E 46}$, had a reduced number of RP2 motoneurons and were therefore considered candidate $p d m-2$ alleles (see Results). The lesion associated with the $p d m$ $2^{E 46}$ mutation was mapped by sequencing genomic DNA that was PCR amplified from the pdm-2-coding region of $p d m-2^{E 46}$ homozygotes. Using primers that anneal to the $5^{\prime}$ - and $3^{\prime}$-untranslated regions as well as primers from the introns of $p d m-2$, each exon was PCR amplified, gel isolated, and sequenced using the Exol-|Pfu Cyclist DNA Sequencing Kit (Stratagene). The identified mutation is a $\mathrm{C} \sim \mathrm{T}$ transition that converts glutamine (CAG) at residue 185 to a stop codon (Dick et al. 1991; Lloyd and Sakonju 1991). Because the POU domain is located between amino acid residues $286-450$, the predicted protein encoded by $p d m-2^{E 46}$ does not contain the known DNA-binding domain. The amino-terminal peptide between residues 1 and 185 includes some opa $(\mathrm{CAX})$ repeats and is rich in acidic residues. The lesion associated with $p d m-2^{E 45}$ has not been mapped.

To identify $p d m-1$ alleles, $>100$ mutations that were lethal over $D f(2 L) P r l$ were made heterozygous over $D f(2 L)$ prd1.7 and tested for loss of RP2 by anti-Eve staining. One allele $p d m-1^{E 37}$ showed a reduced number of RP2 neurons. Its genomic DNA appeared normal as judged by Southern blotting. $p d m-1^{E 37}$ homozygous embryos fail to stain with anti-Pdm-1 antibody but stain normally with anti-Pdm-2 antibody. In situ hybridization of a $p d m$-1-specific probe to embryos collected from a $p d m$ $1^{E 37} / \mathrm{CyO}(f t z-\mathrm{lacZ})$ stock indicated that $p d m-1$ is transcribed in homozygous mutant embryos.

\section{Antibody preparation}

Antiserum recognizing the nonconserved amino-terminal portion of the deduced Pdm-2 protein has been described previously (Yang et al. 1993). A fusion protein containing residues 95-226 from the deduced Pdm-1 protein was produced in Escherichia coli using a modified pGEX vector (Guan and Dixon 1991). The fusion protein was purified by preparative PAGE, as described (Harlow and Lane 1988), and injected into rabbits and mice using complete Freund's adjuvant for the initial inoculation and then incomplete Freund's adjuvant for subsequent inoculations.

\section{Whole-mount staining of embryos with antibodies}

Embryos were fixed and immunostained according to Mitchison and Sedat (1983), with modifications-using secondary antibodies conjugated to biotin and the avidin-biotin complex ( $\mathrm{ABC}$ Kit, Vector Laboratories)—and developed as described by Hsu et al. (1988). In short, embryos were collected, dechorionated with $50 \%$ bleach, fixed with $4 \%$ paraformaldehyde for 20 min, devitellinized with a mixture of $1: 1$ heptane/methanol, washed with methanol, and rehydrated with PBS containing $0.1 \%$ Triton-X $\langle\mathrm{PBT}\rangle$. Anti-Eve (gift from Manfred Frasch, The Mount Sinai Medical Center, N.Y.) and anti-Ftz (gift from the Gehring laboratory, BioZentrum, Basel, Switzerland) were rabbit polyclonal sera. Antibodies directed against bacterial $\beta$-galactosidase were obtained from Sigma. Activity staining and activity/antibody double stainings were performed according to Klaembt et al. (1991). Double antibody staining was performed according to Kania et al. (1990). Unless stated otherwise, all mutant alleles were balanced over "blue balancer" chromosomes that carried an insertion containing $\mathrm{ftz}-\mathrm{lacZ}$ to facilitate the identification of homozygous mutant embryos. For eve $e^{I D I 9} / \mathrm{CyO}(\mathrm{ftz}-\mathrm{lacZ})$, embryo were collected overnight at $18^{\circ} \mathrm{C}$, shifted to $31^{\circ} \mathrm{C}$ for $2 \mathrm{hr}$, and processed immediately for antibody staining.

\section{Microscopy and staging embryos}

Embryos were staged according to the morphological criteria set out by Campos-Ortega and Hartenstein (1985). During stages 10 and 11, staging can be done with the NB arrays (Doe 1992b). Embryos were observed using Nomarski optics with a Zeiss Axiophot microscope.

Confocal microscopy was performed using a Bio-Rad MRC600 scanhead equipped with a krypton/argon laser and a Zeiss Axiophot microscope. For double labeling, the FITC-conjugated anti-mouse secondary antibody was obtained from Boehringer Mannheim; the biotinylated anti-rabbit secondary antibody and avidin/Texas Red complex were purchased from Vector Laboratories.

\section{Identification of GMC4-2a}

The identification of GMC4-2a involves first identifying NB4$2 \mathrm{~A}$, which can be done using the previously decribed NB map (Doe 1992b). GMC4-2a is a smaller cell located near the dorsal/ lateral surface of NB4-2A. It can be identified unambiguously in stage 11 embryos following anti-Pdm-1, anti-Pdm-2, and antiEve staining. Following anti-Ftz staining, however, there is only a short time window near the end of stage 10 when GMC4-2a can be identified unambiguously.

\section{Rescue of mutant phenotype by ectopic expression of heat} shock-inducible transgenes

The following regime was used in the experiments where we ectopically express the $H S p d m-1$ transgene to restore mature 
RP2 neurons in mutant embryos: 2-hr embryo collections were aged for an additional $4.5 \mathrm{hr}$ at $25^{\circ} \mathrm{C}$. The experimental animals were heat-shocked at $37^{\circ} \mathrm{C}$ for $30 \mathrm{~min}$ and the control embryos (no heat shock) were incubated at $25^{\circ} \mathrm{C}$ for an additional $30 \mathrm{~min}$. The embryos were allowed to develop for $\sim 14 \mathrm{hr}$ at $20^{\circ} \mathrm{C}$ prior to anti-Eve staining and analysis. The incomplete rescue seen is not surprising because there is a fine temporal window of around $1 \mathrm{hr}$ during which the $p d m$ functions are required in GMC4-2a for the genesis of RP2 neurons (Yang et al. 1993). It is difficult to coordinate embryo collections with the induction of $\mathrm{Pdm}-1$ expression such that the time of Pdm-1 induction coincides with this temporal window for the majority of the embryos.

\section{Acknowledgments}

We thank Barry Condron, Kai Zinn, and Manfred Frasch for the anti-Eve antibodies; The Corey Goodman laboratory for $\mathrm{mAb}$ BP102 and anti-En; Bob Holmgren and Yu Zhang for the antiGooseberry antibodies; the Walter Gehring Laboratory for anti$\mathrm{Ftz}$; Kathy Matthews, the Bloomington and Tübingen Stock Centers for flies; Ana Busturia, Chris Doe, Nick Harden, Veronica Rodrigues, K. Vijayraghavan, and members of the Sakonju and Chia laboratories for discussion and comments on various forms of the manuscript. This work was supported by the Institute of Molecular and Cell Biology, National University of Singapore, and The European Community (Chia laboratory) and by the Howard Hughes Medical Institute (Sakonju laboratory).

The publication costs of this article were defrayed in part by payment of page charges. This article must therefore be hereby marked "advertisement" in accordance with 18 USC section 1734 solely to indicate this fact.

\section{References}

Artavanis-Tsakonas, S. and P. Simpson. 1991. Choosing a cell fate: A view from the Notch locus. Trends Genet. 7:403408 .

Ashburner, M. 1989. Drosophila: A laboratory manual. Cold Spring Harbor Laboratory Press, New York.

Bate, M. 1976. Embryogenesis of an insect nervous system. I. A map of the thoracic and abdominal neuroblasts in Locusta migratoria. J. Embryol. Exp. Morphol. 35: 107-123.

Baumgartner, S., D. Bopp, M. Burri, and M. Noll. 1987. Structure of two genes at the gooseberry locus related to the paired gene and their spatial expression during Drosophila embryogenesis. Genes \& Dev, 1: 1247-1267.

Bhat, K and P. Schedl. 1994. The Drosophila miti-mere gene, a member of the POU family, is required for the specification of the RP2/sibling lineage during neurogenesis. Development 120: 1483-1501.

Billin, A.N., K.A. Cockerill, and S.J. Poole. 1991. Isolation of a family of Drosophila POU domain genes expressed in early development. Mech. Dev. 34: 75-84.

Bossing, T. and G.M. Technau. 1994. The fate of the CNS midline progenitors in Drosophila as revealed by a new method for single cell labelling. Development 120: 1895-1906.

Cadigan, K.M., U. Grossniklaus, and W.J. Gehring. 1994. Functional redundancy: The respective roles of the two sloppy paired genes in Drosophila segmentation. Proc. Natl. Acad. Sci. 91: 6324-6328.

Campos-Ortega, J.A. 1993. Early neurogenesis in Drosophila melanogaster. In The development of Drosophila melanogaster (ed. M. Bate and A. Martinez-Arias), pp. 1091-1131. Cold Spring Harbor Press, Cold Spring Harbor, New York.
Campos-Ortega, J.A. and V. Hartenstein. 1985. The embryonic development of Drosophila melanogaster. Springer-Verlag, Berlin, Germany.

Chu-LaGraff, Q. and C.Q. Doe. 1993. Neuroblast specification and formation regulated by wingless in the Drosophila CNS. Science 261: 1594-1597.

Coleman, K.G., S.J. Poole, M.P. Weir, W.C. Soeller, and T. Kornberg. 1987. The invected gene of Drosophila: Sequence analysis and expression studies reveal a close kinship to the engrailed gene. Genes \& Dev. 1: 19-28.

Dick, T., X. Yang, S. Yeo, and W. Chia. 1991. Two closely linked Drosophila POU domain genes are expressed in neuroblasts and sensory elements. Proc. Natl. Acad. Sci. 88: 7645-7649.

Doe, C.Q. 1992a. The generation of neuronal diversity in the Drosophila central nervous sytem. In Determinants of neuronal identity (ed. M. Shankland and E. Macagno), pp. 119154. Academic Press, New York.

- 1992b. Molecular markers for identified neuroblasts and ganglion mother cells in the Drosophila central nervous system. Development 116: 855-863.

Doe, C.Q. and C.S. Goodman. 1985. Early events in insect neurogenesis II: The role of cell interactions and cell lineages in the determination of neural precursor cell. Dev. Biol. 111: 206-219.

Doe, C.Q. and G.M. Technau. 1993. Identification and cell lineage of individual neural precursors in the Drosophila CNS. Trends Neurosci. 16: 510-514.

Doe, C.Q., Y. Hiromi, W. Gehring, and C.S. Goodman. 1988a. Expression and function of the segmentation gene fushi tarazu during Drosophila neurogenesis. Science 239: 170 175.

Doe, C.Q., D. Smouse, and C.S. Goodman. 1988b. Control of neuronal fate by the Drosophila segmentation gene evenskipped. Nature 333: 376-378.

Doe, C.Q., Q. Chu-LaGraff, D.M. Wright, and M.P. Scott. 1991. The prospero gene specifies cell fates in the Drosophila central nervous system. Cell 65: 451-464.

Frasch, M., T. Hoey, C. Rushlow, H. Doyle, and M. Levine. 1986. Characterisation and localisation of the even-skipped protein of Drosophila. EMBO I. 6: 749-759.

Golic, K.G. 1994. Local transposition of $P$ elements in Drosophila melanogaster and recombination between duplicated elements using a site-specific recombinase. Genetics 137: 551-563.

Goodman, C.S. and C.Q. Doe. 1993. Embryonic development of the Drosophila central nervous system. In The Development of Drosophila melanogaster (ed. M. Bate and A. MartinezArias), pp. 1091-1131. (Cold Spring Harbor Laboratory Press, Cold Spring Harbor, New York.

Grigliatti, T. 1986. Mutagenesis. In Drosophila: A Practical Approach (ed. D.B. Roberts), pp. 39-58. IRL Press, Oxford, UK.

Grossniklaus, U., R. Kurth Pearson, and W.J. Gehring. 1992. The Drosophila sloppy paired locus encodes two proteins involved in segmentation that show homology to mammalian transcription factors. Genes \& Dev. 6: 1030-1051.

Guan, K. and J.E. Dixon. 1991. Eukaryotic proteins expressed in E. coli: An improved thrombin cleavage and purification procedure for fusion proteins with glutathione S-transferase. Anal. Biochem. 192: 262-267.

Gutjahr, T., N.H. Patel, X. Li, C.S. Goodman, and M. Noll. 1993 Analysis of the gooseberry locus in Drosophila embryos: Gooseberry determines the cuticular patterns and activates gooseberry neuro. Development 118: 21-31.

Hagashijima, S., T. Michiue, Y. Emori, and K. Saigo. 1992. Subtype determination of Drosophila embryonic external sensory organs by redundant homeo box genes BarH1 and 
BarH2. Genes \& Dev. 6: 1005-1018.

Harlow, E. and D. Lane. 1988. Antibodies: A laboratory manual. Cold Spring Harbor Laboratory Press, Cold Spring Harbor, New York.

Hartenstein, V. and J.A. Campos-Ortega. 1984. Early neurogenesis in wild type Drosophila melanogaster. Wilhelm Roux's Arch. Dev. Biol. 193: 308-325.

Herr, W., R.A. Sturm, R.G. Clerc, L.M. Corcoran, D. Baltimore, P.A. Sharp, H.A. Ingraham, M.G. Rosenfeld, M. Finney, G. Ruvkun, and H.R. Horvitz. 1988. The POU domain: A large conserved region in the mammalian pit-1, oct-1, oct-2 and Caenorhabditis elegans unc-86 gene products. Genes \& Dev. 2: 1513-1516.

Hsu, S., G. Ju, and L. Fan. 1988. The glucose oxidase-DABnickel method in peroxidase histochemistry of the nervous system. Neurosci. Lett. 85: 169-171.

Jacobs, J.R., Y. Hiromi, N.H. Patel, and C.S. Goodman. 1989. Lineage, migration, and morphogenesis of longitudinal glia in the Drosophila CNS as revealed by a molecular lineage marker. Neuron 2: 1625-1631.

Jimenez, F. and J. Modolell. 1993. Neural fate specification in Drosophila. Curr. Opin. Genet. Dev. 3: 626-632.

Johnson, W. and J. Hirsch. 1990. Binding of a Drosophila POUdomain protein to a sequence element regulating gene expression in specific dopaminergic neurons. Nature 343: 467470 .

Kania, M.A., A.S. Bonner, J.B. Duffy, and J.P. Gergen. 1990. The Drosophila segmentation gene runt encodes a novel nuclear protein that is also expressed in the developing nervous system. Genes \& Dev. 4: 1701-1713.

Klaembt, C., J.R. Jacobs, and C.S. Goodman. 1991. The midline of the Drosophila central nervous system: a model for the genetic analysis of cell fate, cell migration, and growth cone guidance. Cell 64: 801-815.

Lloyd, A. and S. Sakonju. 1991. Characterisation of two Drosophila POU domain genes, related to oct-1 and oct-2, and the regulation of their expression patterns. Mech. Dev. 36: 87102.

Mitchison, T.J. and J. Sedat. 1983. Localization of antigenic determinants in whole Drosophila embryos. Dev. Biol. 99: $261-264$.

Poole, S.J., L.M. Kauvar, B. Drees, and T. Kornberg. 1985. The engrailed locus of Drosophila: Structural analysis of an embryonic transcript. Cell 40: 37-43.

Prokop, A. and G.M. Technau. 1994. Early tagma-specific commitment of Drosophila CNS progenitor NB1-1. Development 120: 2567-2578.

Robertson, H.M., C.R. Preston, R.W. Phillis, D.M. JohnsonSchlitz, W.K. Denz, and W.R. Engels. 1988. A stable genomic source of $\mathrm{P}$ element transposase in Drosophila melanogaster. Genetics 118: 461-470.

Rothe, M., U. Nauber, and H. Jäckle. 1989. Three hormone receptor-like Drosophila genes encode an identical DNA-binding finger. $E M B O / .8: 3087-3094$.

Rothe, M., M. Pehl, H. Taubert, and H. Jackle. 1992. Loss of gene function through rapid mitotic cycles in the Drosophila embryo. Nature 359: 156-159.

Sambrook, J., E.F. Frisch, and T. Maniatis. 1989. Molecular cloning: A laboratory manual. Cold Spring Harbor Laboratory Press, Cold Spring Harbor, New York.

Thomas, J.H. 1993. Thinking about genetic redundancy. Trends Genet. 9: 395-399.

Tower, J., G.H. Karpen, N. Craig, and A.C. Spradling. 1993. Preferential transposition of Drosophila $P$ elements to nearby chromosomal sites. Genetics 133: 347-359.

Treacy, M.N., X. He, and M.G. Rosenfeld. 1991. I-POU: A POU- domain protein that inhibits neuron-specific gene activation. Nature 350: 577-584.

Udolph, G., A. Prokop, T. Bossing, and G.M. Technau. 1993. A common precursor for glia and neurons in the embryonic CNS of Drosophila gives rise to segment specific lineage variants. Development 118: 765-775.

Vaessin, H., E. Grell, E. Wolff, E. Bier, L.Y. Jan, and Y.N. Jan. 1991. Prospero is expressed in neuronal precursors and encodes a nuclear protein that is involved in the control of axon outgrowth in Drosophila. Cell 67: 941-953.

Yang, X., S. Yeo, T. Dick, and W. Chia. 1993. The role of a Drosophila POU homeodomain gene in the specification of neural precursor cell identity in the developing embryonic central nervous system. Genes \& Dev. 7: 504-516.

Zhang, P. and A.C. Spradling. 1993. Efficient and dispersed local P element transposition from Drosophila females. Genetics 133: 361-373.

Zipursky, S.L., T. Venkatesh, D. Teplow, and S. Benzer. 1984. Neuronal development in the Drosophila retina: Monoclonal antibodies as molecular probes. Cell 36: 15-26. 


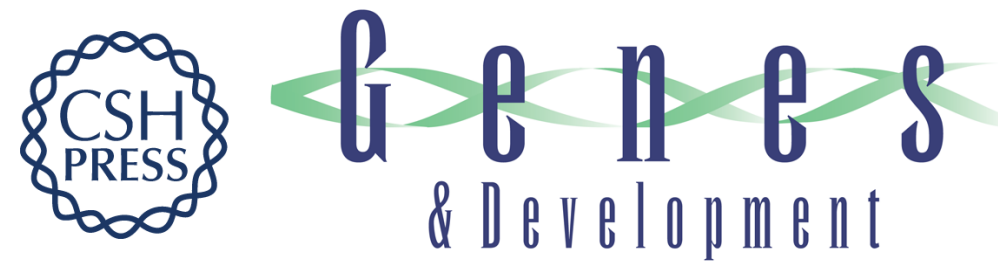

\section{On the functional overlap between two Drosophila POU homeo domain genes and the cell fate specification of a CNS neural precursor.}

S L Yeo, A Lloyd, K Kozak, et al.

Genes Dev. 1995, 9:

Access the most recent version at doi:10.1101/gad.9.10.1223

References This article cites 45 articles, 19 of which can be accessed free at:

http://genesdev.cshlp.org/content/9/10/1223.full.html\#ref-list-1

License

Email Alerting

Service

Receive free email alerts when new articles cite this article - sign up in the box at the top right corner of the article or click here.

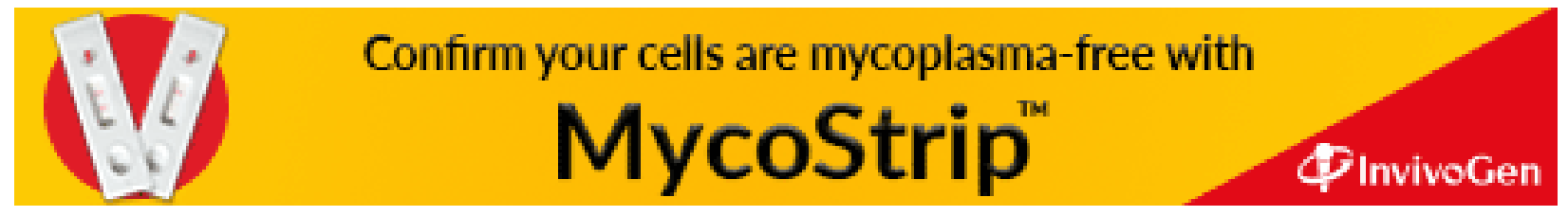

